\title{
Information Technology and Communication in Education: Two Sides of the Coin in Brazil
}

\author{
http://dx.doi.org/10.3991/ijes.v2i2.3814 \\ K. Finardi ${ }^{1}$, D. Teixeira ${ }^{2}$, G. V. V., Prebianca $^{3}$, V. P. dos Santos Júnior ${ }^{4}$ \\ ${ }^{1,2}$ UFES, Vitória, Brazil \\ ${ }^{3,4}$ IF-Catarinense, Santa Catarina, Brazil
}

\begin{abstract}
The objective of this paper is to reflect on the use of Information and Communication Technologies (ICTs) in education in general and in blended approaches in particular. With that aim the study analyzes teachers' and students' beliefs on the use of ICTs in two contexts: a teacher education course for the use of ICTs in blended approaches and an English for Specific Purposes (ESP) course, both offered in the MOODLE platform. The analysis was based on qualitative data from an interview and questionnaires answered by four teachers who took the course and nine learners who attended ESP classes during an academic semester. Results suggest that the use of ICTs in blended approaches by teachers at tertiary level is still scarce. Teachers perceive the incorporation of such resources as an extra burden. Though the course has given them practical and theoretical knowledge about the use of ICTs in blended teaching approaches, it was unable to change their beliefs on the use technology for pedagogical purposes. As for learners' beliefs, results indicate they see the use of ICTs as a way to gain more opportunities for learning, interaction and language improvement, thus validating the use of ICTs in education. Given the divergence of beliefs regarding the use of ICTs in education, on the one hand, and its importance, on the other, the study concludes that while pedagogical practices are not aligned with the social context and demands of society, teachers may continue to perceive a low level of motivation and engagement on the part of students.
\end{abstract}

Index Terms-Blended Learning, Information Technology and Communication; Teachers' and Students' Beliefs.

\section{INTRODUCTION}

Information and Communication Technologies (hereafter ICTs) are present in most public schools and universities in Brazil. Teachers, students and educational agents use ICTs everyday and are now trying to incorporate these tools in educational contexts so as to improve the quality and relevance of educational experiences in the era of cyber culture [1]. Yet, what teachers and students think of and how they incorporate these ICTs in education is still not known.

According to Ref. [2], beliefs can be inferred both from what people say and from what people do. Teachers' beliefs and knowledge are said to shape their mental acts, which in turn, guide their actions and decisions [3], affecting learning outcomes. Ref. [4] suggests that when information is not available (in the form of theory or knowledge), teachers will rely on beliefs to guide them. Ref. [5], in a study of teachers' beliefs, found that experienced teachers rely more on beliefs than on theory (knowledge), even when the latter is available. Teachers filter the theory (knowledge) through their beliefs on teaching, which are, in turn, grounded in their experience, adapting them to their reality.

How teachers know what they know has been studied in general educational research [6], [7]. A number of studies in the field of general education have focused on how teachers construct their philosophies and theories of teaching [8].

Students' beliefs are also said to play a decisive role in their success and failure in language learning [9] since their perceptions about their learning model is considered by them more significant than any theoretical approach to language learning [10]. Therefore, unveiling what language students believe regarding the use of computer and Internet-based materials to learn English for specific purposes (ESP) seems to be of great help for teachers in trying to design appropriate ESP instruction in the highly technological world we live in nowadays.

This technological and globalized world enabled a faster and cheaper flux of information with the help of ICTs which connect millions of users through mobile phones, internet and social networks. This new flux of information changed the way we act and interact in this new global and local scenario, which is also real and virtual. The new ICTs also changed the way we access and produce information and knowledge as can be seen in the number of Massive Online Open Courses (MOOCs) offered by world class universities [11].

In Brazil the power of social networks became evident in the protests that broke out in June 2013 and which were organized through Facebook. We can say that internet made access to information available and provided an expression channel (mostly through social networks) for millions of people worldwide. Given the prevalence of Facebook and the number of users in Brazil it would be reasonable to expect that this tool could be used for pedagogic purposes too, especially in the case of language learners who can access different registers, cultures and languages through this social network. Yet, in the case of foreign language learning this is not the case and this tool still seems to be, like many other ICT tools, underused in educational contexts in Brazil.

Ref. [12] analyzed the pedagogic possibilities of Facebook for English as a foreign language (EFL) practice contrasting them to second language acquisition theories and concluded that Facebook represents great pedagogical potential for EFL practice. Yet, two other studies showed that this pedagogic potential is not taken into 
consideration by teachers. Ref. [13] analyzed the use of Facebook as a communication tool between teachers and students and Ref. [14] analyzed teachers' and students' beliefs on the use of Facebook for EFL learning and both studies concluded that despite the pedagogic potential of Facebook for EFL practice and learning, this social network is still not seen as a pedagogic tool and is not incorporated in educational practices in Brazil.

The transformations perceived and reflected on the ways in which we communicate and produce knowledge usually reach domestic environments faster than educational ones. Given the pressing need to incorporate ICTs in pedagogical contexts, the present study offers a contribution by analyzing two sides of the coin in the use of ICTs in Education in Brazil: the teaching and the learning sides as revealed by tertiary teachers' and English for Specific Purposes (ESP) students' beliefs on the use of ICTs for pedagogical purposes.

Ref. [15] claim that in the information era we live where most of the content is transmitted in English and by clicks, both knowledge of English and digital literacy are passports to access information online to build social capital [16]. According to the same authors [15], internet represents access to information and social inclusion in the globalized world though not all teachers reflect about their role in this new society and often resist changes in their pedagogical practices so as to incorporate internet and ICTs in their teaching practices, making learning experiences more relevant and shared.

Formal educational spaces should be repositories of new practices which build, adapt and change languages, interactions, contexts and roles in education. These changes often bring about tensions between traditional models of education and education models that are more aligned with the information era we live in. Teachers' resistance to the incorporation of ICTs in blended approaches represents one such tension in the Brazilian educational system which is struggling to become more aligned with the $21^{\text {st }}$ century education.

A study on ICTs in Education in Brazil, published in 2010 by the Internet Management Committee revealed that most public schools have television, DVD and VHS player and printer. The gap in the regional distribution of technological infrastructure can be observed in the number of phone landlines: $81 \%$ of schools have phone landlines in Brazil whereas $73 \%$ have in the North and NorthWestern regions and only $55 \%$ have phone landlines in the Northeast region. Digital cameras and video recorders are present in $78 \%$ and $42 \%$ of schools, respectively. Most schools have an average of 23 computers whereas this number drops to 19 in the Northeast, especially when compared to the 27 in the South. Another study on the relationship between teachers and ICTs by the Information and Communication Center of Technology in Brazil reported the following numbers in 2011: $94 \%$ of teachers have a personal computer and $98 \%$ used internet in the last 3 months, also, $89 \%$ of teachers have internet home access and use it at least once a week. Moreover, the study reported that teachers have little or no difficulty in performing the following tasks: copying and moving files (65\%); using text editors (78\%); using presentation editors (78\%); using spreadsheets (26\%); using multimedia (42\%); internet search (87\%); e-mails (83\%); sending instant messages $(70 \%)$; participating in discussion forums (47\%); participating in social sites $(60 \%)$; using blogs and updating internet pages $(25 \%)$; posting films and videos in the internet (32\%); using internet for making phone calls $(22 \%)$; downloading and installing programs (35\%); online shopping (50\%); distance learning (47\%).

According to the numbers shown here it is possible to say that schools are equipped with ICT tools and equipment though, as this paper suggests, the problem regarding the link between ICTs and social capital is not in terms of the simple access to technologies but rather how this access has been appropriated by teachers and students to produce social capital [16].

Ref. [16] describes two types of access to technology (ICTs) that may lead to the construction or appropriation of social capital. According to the author, physical access to computers and ICTs does not guarantee access to the information society. To help ensure that the first type of access translates into the second, it is necessary to pay attention to how computer and internet use can enhance social capital. This study was partially motivated by the observation that it is necessary to guarantee the second type of access to ICTs in all levels of education in Brazil and in both sides of the coin, namely: teaching and learning.

Regarding the use of ICTs by tertiary teachers - the teaching side of the coin, the study aims at describing a teacher continuing education course offered online for the use of ICTs in regular classes and blended approaches at a Federal University in Brazil and teachers' beliefs on the course. Regarding the use of ICTs by students - the learning side of the coin, the present study scrutinizes students' perceptions concerning the use of a virtual learning environment to learn English for specific purposes (ESP) at a Federal Institute in Brazil. Both the Federal University and the Federal Institute of Education, Science and Technology are federal autarchies with different attributions. Whereas a federal university offers undergraduate and graduate programs, federal institutes offer technical e technologic education in professional high school courses and technologist undergraduate courses. In what follows the two courses offered in the MOODLE platform are described.

\section{A. Teachers' Course}

A continuing education course for the use of ICTs in face-to-face classes and blended approaches was proposed after the observation in a Federal University in Brazil that out of the 1.246 teachers and 2.245 technical staff of that university only $30 \%$ used ICTs systematically in face-toface classes and only $3 \%$ of them used Virtual Learning Platforms. Given the little use of ICTs at the university investigated, the course was proposed so as to help the understanding of new teaching practices marked by the transformation of teacher roles and the reconfiguration of information transmission and processing [17], [18], [19].

The course was implemented and offered in the Moodle platform for distance courses and the syllabus included the following modules: a) Setting of Moodle and Web Conference tools; b) Mediation tools for distance learning; c) Media integration in Education I; d) Media integration in Education II; e) Foundations of Distance Education. Two hundred vacancies were offered for free for the course but not all were taken. Since the number of teachers who registered for the course was smaller than the number of vacancies offered for the course, a second registration call was made and the course was also offered for the technical and administrative staff of the university. 
A total of 176 students took the course, 57 of whom were teachers and 119 of whom were technical or administrative staff at the university. Given the fact that the course was offered for free and online, the number of teachers who registered for the course is, in itself, important data for it reveals that most teachers were not interested in taking the course or incorporating ICTs tools in their teaching practice. The course aimed at: sharing knowledge concerning the use of new ICTs in face-toface, blended and online educational contexts; producing and publishing contents using ICTs; and motivating the use of ICTs for pedagogical and academic purposes. Eight tutors participated in the course after a 40 hour training in the Moodle platform which was selected for its possibility of (i) creation and management of study groups; (ii) creation of forums; (iii) creation of users profile and groups; (iv) use of tools such as Chat, Forum and virtual libraries; and (v) users interaction and access to on-line materials.

\section{B. Students' Course}

As established by the Ministry of Education in Brazil in its national catalogue for undergraduate courses in Technology, the Technologist in Systems Analysis and Design is in charge of analyzing, designing, documenting, specifying, testing, installing and maintaining informational and computational systems. Some of the essential skills necessary for this profession are logical reasoning and knowledge of language programming. The technical course lasts two thousand hours.

The Technologist in Systems Analysis and Design course held at the Federal Institute of Education, Science and Technology investigated offers 35 vacancies once a year and lasts a minimum of six academic semesters. The main academic area deals with Java language programming, systems analysis, software engineering, data base, web systems design, desktop and mobile devices. The main objective of the course is to promote the building of solid concepts and techniques to systems analysis and development so as to fulfill the needs of the community where the Institute is situated, namely, a technological hub in the south of Brazil.

The students invited to participate in this study were freshmen enrolled at the first academic semester in which the ESP course is offered with a total of 60 hours. The syllabus of the course requires the study of vocabulary in the IT/computing area; reading strategies and basic verbal tenses; translation of texts, and writing of technical documents.

The ESP classes which served as the context for data collection consisted of 18 meetings and were taught in the first academic semester of 2013 at the computing laboratory of the Institute. During the classes, students were introduced to the use of Moodle and performed several computer- and internet-based activities such as watching videos at YouTube, listening to original informative texts in English, reading, doing interactive grammar exercises, participating in forums, writing texts, among others. Students were also encouraged to actively participate not only during face-to-face classes but also in asynchrony tasks in the virtual learning environment whenever possible as a way to improve their interaction with other students by using the English language. All activities performed in the Moodle along the term were scored and inserted in the calculations for their course final grade.

\section{Methodology}

In order to reveal teachers' and students' beliefs on the use of ICTs in general and on the Moodle platform in particular, this study analyzes qualitative data from questionnaires and interviews with four out of the 57 teachers enrolled at the continuing education course for the use of ICTs offered at the university investigated, and with nine ESP students enrolled at an undergraduate course in the institute investigated.

Regarding the teaching side of the coin, a questionnaire with 27 questions [19] was answered by four teachers, who were later interviewed regarding their beliefs on the use of ICTs in blended approaches and their perceptions on the Moodle platform used in the course.

In what concerns the learning side of the coin, a questionnaire with 10 semi-structured questions was answered by nine ESP students after having experienced the use of Moodle during a whole academic semester.

Data were analyzed qualitatively and is presented in what follows.

\section{Results}

This section is two-fold. First, the results of teachers' beliefs regarding the use of ICTs in Education (the teaching side of the coin) is presented. Next, students' perceptions and assessment of the Moodle platform (the learning side of the coin) is reported and followed by a discussion of the data.

\section{1) Teachers' beliefs}

During the interview all teachers said that the course helped them envisage different possibilities of use of ICTs both in face-to-face classes and in blended approaches and claimed to have no difficulties in taking the course in the Moodle platform. When asked whether they had incorporated some of these possibilities in their classes they said that to some extent they had, but not as much as they thought they could, given the time and planning required to use some of these ICTs in blended approaches. Teachers were then asked to explain what where the main challenges to incorporate ICTs in blended approaches and they said that access to equipment, which had to be reserved in advance, was the main problem. In the university where the study was conducted access to the laboratory or data show equipment was available upon reservation and prior planning. They also said that some types of equipment required the presence of a technician to operate the equipment and these staff members were not always available when teachers needed them so they preferred to plan their classes independent of the presence of technicians.

Teachers also answered a questionnaire which asked how well they could do certain activities. The 27 questions of the questionnaire were whether teachers could, after the course: 1 . Identify the people in charge of support of ICTs and their specific functions within and outside the institution; 2. Become familiar with the different IT elements such as resources, programs and tools in their professional environment ; 3. Select and use the resources and services available in a digital workspace; 4. Select and use the most appropriate tools for communication with different members and users of the educational system; 5. Organize and access resources and documents using professional and institutional sources; 6. Use Open and Distance Learning devices or 
online resources in their training; 7. Consult research that combines knowledge, learning and ICT in education; 8 . Make pedagogical and institutional monitoring related to the scope of the discipline or level of education taught using ICT; 9. Express and communicate adapting to different audiences and broadcast spaces; 10. Consider the challenges and risks as well as meet the standards with respect to the search and control criteria of validity of information, Internet safety and filtering; 11. Consider the laws and requirements of professional use of ICTs especially in relation to the protection of individual and public liberties, safety, protection of minors, confidentiality with respect to the data, intellectual property and copyright and images; 12 . Respect and make respect the rules of the institution in an educational perspective of civic learning; 13. Find, produce, share and exchange documents, information and resources in a digital environment; 14. Assist in a production or a collective project with disciplinary, interdisciplinary, cross or educational teams; 15 . Develop situations of information seeking in the context of cross-cutting and interdisciplinary projects; 16 . Identify appropriate learning situations for the use of ICTs; 17. Plan learning situations and evaluations using programs within the content taught or the course grade level; 18. Integrate tools and resources in a class selecting the media means and methods of use; 19. Prepare communication resources adapted to diverse public and educational situations; 20. Drive learning situations by taking advantage of the potential of ICTs in collective and individual work, small groups and search documents; 21. Administer switchover, during class, between activities with and without ICTs; 22. Consider the diversity of students and academic difficulty of using ICTs in the administration of the time and modes of teaching; 23. Use ICTs to accompany students in their production projects; 24 . Anticipate a technical problem; 25. Identify the skills of ICTs used by students in a training situation; 26. Participate in a collective approach to skill assessment for the use of ICTs; 27. Use the information on the level of mastery of ICTs for their students in activities programming.

The questionnaire allowed four types of answers: 1) the teacher felt incapable of doing the activity, 2) they felt they could do the activity with help, 3) they felt they could do the activity on their own or 4) they felt they could do the activity as a specialist assisting others. Most teachers answered that they could do these activities on their own after the course. None of them answered they could not do or could do only with help the activities mentioned in the questionnaire. Thus, overall the analysis of the questionnaire shows that the teachers who took the course and answered the questionnaire feel more capable, after taking the course, of using ICTs in educational contexts. However, the interview showed that although teachers were able to use ICTs in pedagogical contexts at the university, they were not willing to do so, given the technical difficulties and extra burden this incorporation represented in terms of planning, reserving equipment and being assisted by technicians. It seems that teachers are familiar with the tools and have access to them but do not see the benefit of using them in their pedagogical practice or perhaps do not consider the benefits to be greater than the burden of incorporating ICTs in their teaching practice. In other words, the course seems to have given teachers more theoretical and practical knowledge on
ICTs but it was unable to change their beliefs (and or practice) regarding the use of ICTs in education.

\section{2) Students'Beliefs}

Students were asked to rate their level of satisfaction $(1=$ totally satisfied to $5=$ totally unsatisfied) regarding the use of the Moodle Platform in the face-to-face ESP classes. Forty-five percent answered 1, 22\% percent answered 2, nobody answered 3,11\% answered 4 and $22 \%$ answered 5 . When asked to justify their answers the students replied that the course was updated, dynamic, interactive and more motivating than traditional classes. One student also said that the Moodle is the best option for academic courses and sharing.

When asked whether the Moodle platform had contributed to their learning of English all students said yes and reported that having the possibility to access links directly from the internet, through the platform, enables the practice of the four skills (listening, reading, writing and speaking) in an integrated fashion. Two students also claimed that the platform, allied with the possibility of accessing contents in the internet helped the practice of listening in particular. Students also claimed that it is best to clarify doubts when they arise and that is possible with the platform which offers feedback and the possibility to check content online.

Students were then asked to rate the level of difficulty of working with the Moodle platform to learn English ( $1=$ extremely easy to $5=$ extremely difficult). Sixty-seven percent answered 1, 11\% answered 2, 11\% answered 3, no one answered 4 and $11 \%$ answered 5 .

Students were also asked to name the main contribution of the Moodle platform for their learning of English. Twenty-five percent said that they improved the listening skill, $22 \%$ said that it helped to learn vocabulary, $22 \%$ said that it helped to improve the reading skill and 6\% said that it helped with the speaking skill.

Finally, students were asked about their preferences regarding teaching methodologies. Fifty-six percent said they prefer a technological approach (the one that is taught exclusively by means of a virtual learning environment such as Moodle and computer/Internet-based materials and activities), 33\% said they prefer a hybrid or blended approach and $11 \%$ claimed to prefer the traditional approach (the one that focuses on paper-based materials and activities and expositive classes).

\section{E. Discussion}

The analysis of the data in this paper shows that teachers felt capable of using ICT tools in pedagogical contexts after a continuing education course offered for the use of ICTs in education; the course offered for teachers seemed to have changed their theoretical and practical knowledge of ICTs but not their practice or beliefs regarding the benefits and potential of incorporating ICTs in their teaching practices. The analysis of students' beliefs shows that most learners enjoyed the course in the Moodle platform and prefer a technological approach to ESP learning. This finding might be related to participants' technological profile, given the undergraduate course they were taking.

Taken together, the results of the present study indicate that the presence of ICTs in teaching and learning practices in Brazil might not represent two sides of the same coin. In other words, there seems to be a divergence between teachers' and students' beliefs on the use of ICTs 
in education - while the teaching side sees the incorporation of ICTs to a pedagogical routine as extra amount of work and preparation, the learning side seems to validate their value as relevant pedagogical tools. These findings may explain the phenomenon of low motivation and engagement reported by teachers when addressing reasons for students' poor achievement.

\section{F. Conclusion}

The study reported in this paper aimed at describing (i) a continuing education course for the use of ICTs in educational contexts at tertiary level, (ii) revealing teachers' beliefs on the use of ICTs in face-to-face and blended classes, and (iii) assessing students' perception on the use of an ESP course offered in the Moodle. In general, results of the study suggest that teachers are not actively engaged with the use of ICTs in educational contexts and though they have no problem to access ICTs in formal educational settings, their use of ICTs is still limited. Teachers still seem to believe that planning classes for the use of ICTs in advance, booking the equipment needed and carefully thinking about how to approach the most suitable ICT for a particular class represents extra work and requires more time and planning, which teachers do not always seem to have.

Regarding students' perceptions on the use of Moodle in face-to-face ESP classes, the platform was seen as a way to provide students with more opportunities for learning than the traditional ESP classes that are usually limited to paper-based materials and activities. According to the learners, the technological approach is more motivating, dynamic and allows them to interact more in the English language.

Taken together results of this study point to a gap between teachers' and students' beliefs on the use of ICTs in education in Brazil. Whereas teachers resist the incorporation of ICTs in education for reasons that vary between the extra burden represented by its incorporation and the perceived need for more investment in teacher education in general and for the use of ICTs in particular, students seem to have a clear preference for technological, or at least, blended approaches. Finally, these findings can be taken as evidence that while pedagogical practices are not aligned with the social context and demands of society, teachers may continue to perceive a low level of motivation and engagement on the part of students.

\section{REFERENCES}

[1] P. Lévy. Cibercultura. São Paulo: Editora 34.1999.

[2] M.F. Pajares, M.F. (1992). "Teachers'beliefs and educational research: cleaning up a messy construct". Review of educational research, 62/3, 307-332.1992. http://dx.doi.org/10.3102/003465 43062003307 [3] E. Gatbonton, "Investigating
teachers'pedagogical knowledge." Journal, 83 (1), 35-50.1999.

[4] D. Woods. Teacher cognition in language teaching. Beliefs, decision making and classroom practice. Cambridge: Cambridge University Press.1996.

[5] D. Binnie-Smith. "Teacher decision making in the ESL classroom." In D. Freeman \& J. Richards (Eds), Teacher learning in language teaching. Cambridge: Cambridge University Press.1996.

[6] D. Schon. The reflective practitioner. London: Temple Smith.1983.

[7] K. M. Zeichner, K. M. "Educating reflective teachers for learnercentered education: possibilities and contradictions." Plenary paper presented at the sixteenth Meeting of Encontro Nacional de Professores Universitários de Língua Inglesa, University of Londrina, Brazil. 2001.

[8] D. J. Clandinin and F. M. Connelly. "Teachers' personal knowledge: What counts as personal in studies of the personal." Journal of Curriculum Studies, 19. 1987.

[9] Akbari and Youran. "Assessing ESP learners' beliefs about language learning: a survey in an Iranian local context." The International Journal of Language Learning and Applied Linguistics World (IJLLALW), 3(2), June, 73-82. 2013.

[10] J. C. Shin and U. Teichler. The Future of The Post-Massified University at the Crossroads. Restructuring Systems and Functions. Jung Cheol Shin and Ulrich Teichler (Editors). Springer. 2014

[11] K. Finardi, J. Covre, L.Santos, S. Peruzzo and C. Hildeblando Junior. "Facebook as a tool for L2 practice". Revista Contextos Linguísticos, v. 7, p. 312-325. 2013.

[12] K. Finardi and T. Veronez. "Beliefs on the use of facebook as a communication tool between teachers and students". Revista Contextos Linguísticos, v. 7, p. 292-311. 2013.

[13] K. Finardi and B. Pimentel. "Crenças de professores de inglês sobre o uso do Facebook". Revista Contextos Linguísticos, v. 7, p. 238-253. 2013.

[14] K. Finardi, G. Prebianca and C. Moom. "Tecnologia na Educação: o caso da Internet e do Inglês como Linguagens de Inclusão." Revista Cadernos do IL, vol. 46. p. 193-208.2013.

[15] M. Warschauer. "Social capital and access". Universal Access in the Information Society, 2. 2003.

[16] J. F. Cerisier. "Culture numérique versus culture scolaire". Revue de l'AFAE, $n^{\circ} 117, p .11-23,2008$.

[17] J. A. Valente. "Curso de especialização em desenvolvimento de projetos pedagógicos com o uso de novas tecnologias: descrição e fundamentos". In: J. A. Valente; M. Prado, M. Almeida, (Orgs.) Educação a distância via internet. São Paulo:Avercamp, 2003.

[18] MEC. Catálogo Nacional de Cursos Superiores de Tecnologia, 2010.

[19] M.C. Moraes. "Educação a distância e a ressignificação dos paradigmas educacionais: fundamentos teóricos e epistemológicos". In: M.C. Moraes, L. Pesce, A. R. Bruno (Orgs.). Pesquisando fundamentos para novas práticas na educação online. São Paulo: RG Editores, 2008.

[20] D. Teixeira and K. Finardi. "Tics no ensino presencial: evidências de um curso de formação continuada na Universidade Federal do Espírito Santo". Contextos Linguísticos, v. 7, p. 79-96. 2013.

\section{AUTHORS}

K. Finardi is with the Education, Language and Culture Department and the Post-Graduation Programs of Linguistics (PPGEL- http://www.linguistica.ufes.br/) and Education (http://www.ppge.ufes.br/) of the Federal University of Espirito Santo (http://www.ufes.br/), Brazil (e-mail: kyria.finardi@gmail.com).

D. Teixeira is with the Education, Language and Culture Department of the Federal University of Espirito Santo (http://www.ufes.br/), Brazil (e-mail: daisat@uol.com.br).

G. V. V. Prebianca is with the Catarinense Federal Institute - $\quad$ Blumenau campus. (http://blumenau.ifc.edu.br/principal/). 81, Bernardino José Oliveira Street. Blumenau, Santa Catarina. Brazil. (email: gicele.prebianca@blumenauu.ifc.edu.br.

V. P. dos Santos Júnior is with the Catarinense Federal Institute - Blumenau campus (http://blumenau.ifc.edu.br/principal/). 81, Bernardino José Oliveira Street. Blumenau, Santa Catarina. Brazil. (email: vital.junior@blumenauu.ifc.edu.br.

Submitted 29 April 2014. Published as re-submitted by the authors 18 May 2014. 